\title{
PROMOVENDO O ENSINO DE PORTUGUESS LÍNGUA ESTRANGEIRA MEDIADO POR TEXTOS MULTIMODAIS EM PRÁTICAS EXTENSIONISTAS
}

\author{
FOMENTO DE LA ENSEÑANZA DEL PORTUGUÉS COMO LENGUA EXTRANJERA \\ MEDIADA POT TEXTOS MULTIMODALES EN PRÁCTICAS DE EXTENSIÓN
}

\author{
PROMOTING PORTUGUESE AS FOREIGN LANGUAGE TEACHING MEDIATED BY \\ MULTIMODAL TEXTS IN EXTENSION PRACTICES
}

\author{
Marta Lúcia Cabrera KFOURI ${ }^{1}$
}

\begin{abstract}
RESUMO: Neste artigo, apresentamos alguns resultados do uso de textos multimodais no ensino de Português Língua Estrangeira (PLE) oferecido em projeto de extensão, junto a uma universidade pública. Os participantes são estrangeiros de distintos países, em situação de imersão acadêmica e social na cidade onde a universidade está inserida. O objetivo é caracterizar o texto multimodal como recurso para experiências interculturais e humanizadoras de aprendizagem significativa da língua (COSTA VAL, 2004), especialmente trabalhados em grupo da rede social Facebook. Os resultados sugerem que, embora não tenha propósitos educacionais, a rede social em questão revelou-se como ambiente com potencial para a humanização da aprendizagem, por suas possibilidades de interação, socialização e comunicação na língua-alvo, funcionando como ferramenta de aprendizagem interculturalista e colaborativa online (FINARDI; PORCINO, 2016). Os usos de textos multimodais, por suas caraterísticas, promoveram alta conectividade e expansão entre conteúdos já trabalhados nas aulas e outros complementares.
\end{abstract}

PALAVRAS-CHAVE: Português língua estrangeira. Textos multimodais. Ensino interculturalista e humanizador. Projeto de extensão. Universidade pública.

RESUMEN: En este artículo presentamos algunos resultados del uso de textos multimodales en la enseñanza del Portugués como Lengua Extranjera (PLE) ofrecidos en un proyecto de extensión en una universidad pública. Los participantes son extranjeros de diferentes países, en situación de inmersión académica y social en la ciudad donde se ubica la universidad. El objetivo es caracterizar el texto multimodal como recurso para experiencias interculturales y humanizadoras de aprendizaje significativo de idiomas (COSTA VAL, 2004), especialmente trabajado en grupo en la red social Facebook. Los resultados sugieren que, si bien no tiene fines educativos, la red social en cuestión se reveló como un entorno con potencial para la humanización del aprendizaje, por sus posibilidades de interacción, socialización y comunicación en la lengua meta, funcionando como un medio intercultural y herramienta de aprendizaje colaborativo online (FINARDI y PORCINO, 2016). El uso de textos multimodales, por sus características, promovió una alta conectividad y expansión entre contenidos ya trabajados en las clases y otros complementarios.

${ }^{1}$ Universidade Estadual Paulista (UNESP), Instituto de Biociências, Letras e Ciências Exatas (IBILCE), São José do Rio Preto - SP - Brasil. Professor Assistente Doutor, Departamento de Educação. ORCID: https://orcid.org/0000-0001-7909-5599. E-mail: marta.kfouri@unesp.br 
PALABRAS CLAVE: Portugués Lengua Extranjera. Textos multimodales. Enseñanza interculturalista y humanizadora. Proyecto de Extensión. Universidad pública.

ABSTRACT:In this article, we present some results of the use of multimodal texts in teaching Portuguese as a Foreign Language (PFL) offered in an extension project at a public university. Participants are foreigners from different countries, in a situation of academic and social immersion in the city where the university is located. The objective is to characterize the multimodal text as a resource for intercultural and humanizing experiences of meaningful language learning (COSTA VAL, 2004), especially worked in a group on the social network Facebook. The results suggest that, although it has no educational purposes, the social network in question revealed itself as an environment with potential for the humanization of learning, due to its possibilities of interaction, socialization and communication in the target language, functioning as an intercultural and learning tool. collaborative online (FINARDI and PORCINO, 2016). The use of multimodal texts, due to their characteristics, promoted high connectivity and expansion between contents already worked on in classes and other complementary ones.

KEYWORDS: Portuguese as foreign language. Multimodal texts. Intercultural and humanizing teaching. Extension project. Public university.

\section{Introdução}

A linguagem é um importante meio de humanização das relações sociais, já que todas as interações são permeadas por ela. Quando se trata de abordar uma nova língua em contexto de imersão, no qual os aprendizes necessitam interagir para sobreviver e constituir novas relações sociais, de trabalho ou de estudo, a tarefa de humanizar o discurso torna-se ainda mais relevante. Para Matos (2010), é fundamental favorecer a autoimagem positiva e a autoestima linguística dos aprendizes, promovendo-lhes uma confiança mínima como usuários da língua que lhes garanta, consequentemente, uma autoestima lexical, gramatical, argumentativa e cultural, ensinando-os a "comunicar-se para o bem".

Nesse cenário, a internet transformou os modos como nos comunicamos, adquirimos informação e aprendemos. Além disso, a rede permite cada vez mais o acesso das pessoas a repertórios discursivos e culturais construídos em outras línguas (MOITA LOPES, 2013), que nos chegam de várias partes do mundo, ou até mesmo do próprio Brasil. Diante da velocidade com que a informação é produzida e divulgada, surgem os textos multimodais, que trazem consigo características compatíveis com o espaço virtual em que são produzidos. Além de possuírem grau elevado de criatividade em sua composição, textos multimodais, que são, ao mesmo tempo, orais, escritos e imagéticos, carregam traços de outras produções encontradas fora do âmbito digital, promovendo empatia e gerando identificação do leitor. Por tais 
características, consideramos que essas manifestações discursivas têm potencial como insumo didático em contextos de ensino-aprendizagem de português língua estrangeira (doravante $\mathrm{PLE})^{2}$, já que facilitam a aprendizagem, humanizam o discurso e promovem mecanismos de interculturalidade e pertencimento.

Neste artigo, no qual abordamos especificamente o ensino de PLE por meio de experiências humanizadoras em projeto de configuração extensionista desenvolvido em uma universidade pública, apresentamos como recurso didático textos multimodais trabalhados em grupo da rede social Facebook, com destaque aos memes (embora não sejam os únicos utilizados), que são produções de humor geradas em ambiente virtual a partir de temas cotidianos e da linguagem coloquial $^{3}$. Seu uso justifica-se por considerarmos que a familiaridade dos estudantes com tais textos multimodais pode facilitar a aprendizagem de português por meio de atividades que favoreçam a leitura e a produção escrita na língua-alvo, bem como a comunicação significativa e criativa na língua.

Os participantes são estrangeiros de distintos países, em situação de imersão acadêmica e social na cidade onde a universidade está inserida. Nosso objetivo é caracterizar o texto multimodal como recurso para experiências interculturais e humanizadoras de aprendizagem significativa da língua (COSTA VAL, 2004), especialmente trabalhados em grupo da rede social Facebook, tal como destacamos acima. Os resultados sugerem que, embora não tenha propósitos educacionais, a rede social em questão revelou-se como ambiente com potencial para a humanização da aprendizagem, por suas possibilidades de interação, socialização e comunicação na língua-alvo, funcionando como ferramenta de aprendizagem interculturalista e colaborativa online (FINARDI; PORCINO, 2016). Além disso, o uso de textos multimodais, por suas caraterísticas, promoveu alta conectividade e expansão entre conteúdos já trabalhados nas aulas e outros complementares.

${ }^{2}$ O termo "língua estrangeira" é atribuído ao português ensinado como outra língua, de acordo com a SIPLE Sociedade Internacional de Português Língua Estrangeira.

${ }^{3}$ Este artigo é uma adaptação da conferência intitulada "A linguagem humanizadora no ensino de PLE com textos multimodais: experiências em rede social em um projeto extensionista de universidade pública", que compôs a mesa-redonda "O ensino de PLE mediado por textos multimodais: reflexões didático-metodológicas", durante o I Congresso Internacional de Português Língua não Materna (CIPLíNM- UNESP), realizado pela FCLAr- UNESP, nos dias 04 e 05 de dezembro de 2019 


\section{$O$ contexto extensionista}

O contexto maior de desenvolvimento do ensino de PLE é o Projeto de Extensão "Português Língua Estrangeira (PLE)"4, cujas atividades tiveram início no primeiro semestre de 2012, no campus da Unesp de São José do Rio Preto, ainda como evento de extensão. Naquele momento, o objetivo maior era atender a demanda emergencial de alunos estrangeiros de graduação e de pós-graduação, os quais tinham necessidade primordial de estudar ou dar continuidade a estudos em língua portuguesa para comunicar-se nas aulas na universidade; expressar-se escrita e oralmente em diferentes situações; e conviver socialmente em seus novos espaços de atuação (vida acadêmica e pessoal). Com o passar do tempo, já cadastrado como projeto de extensão, nosso trabalho com o PLE passou a ter um alcance maior em termos de público-alvo, cumprindo sua tarefa extensionista de atender, sobretudo, a comunidade externa. Podemos dizer que, até 2015, a maioria eram alunos estrangeiros de graduação e de pós-graduação do IBILCE/UNESP, quando, naquele ano, oferecemos um curso especial e emergencial para atender vinte e sete refugiados sírios. A partir de 2016, estabeleceu-se um equilíbrio entre estrangeiros das comunidades externa e interna e, a partir de 2018, notamos uma predominância de estrangeiros da comunidade externa, constituída especialmente de refugiados haitianos, sírios e venezuelanos, a maioria deles com formação superior ou ensino médio, que precisam da língua portuguesa para comunicar-se em situações sociais e ingressar no mercado de trabalho.

Quanto à configuração do projeto, além das aulas presenciais oferecidas duas vezes por semana (1h40min cada), os alunos tinham atividades complementares de oralidade e escrita. Atualmente, esses cursos continuam em caráter remoto, com atividades remodeladas ao contexto de distanciamento pandêmico. De qualquer forma, o projeto PLE tem configuração extensionista, com potencial para desenvolver: Atividades de ensino (cursos de língua e preparatórios para o exame CELPE-Bras); Atividades de aperfeiçoamento linguístico-cultural (Puxa-Conversa; Cineclube PLE; Coral de Estrangeiros; minicursos temáticos); Atendimento social e humanitário (Refugiados e imigrantes em geral, em parceria com a Secretaria Municipal do Trabalho, igrejas e outros centros comunitários); Atividades culturais (I e II Mostra Intercultural de Estrangeiros do PLE/IBILCE; Recitais do Coral dos Estrangeiros; excursões); Atividades tecnológicas, científicas, acadêmicas e de formação docente (cursos de aperfeiçoamento para professores de PLE; reuniões pedagógicas;

${ }^{4}$ Projeto de extensão desenvolvido junto à Pró-reitora de Extensão universitária (PROEX) da Universidade estadual paulista "Júlio de Mesquita Filho" (UNESP), no Instituto de biociências, Letras e ciências exatas (IBILCE), São José do Rio Preto. 
orientações de IC; apresentações de trabalhos em simpósios; organização de livro; criação de disciplina obrigatória do curso de Licenciatura em Letras; dissertações de mestrado; site e página no Facebook e Instagram; entrevistas).

No que tange aos objetivos, vislumbramos, assim, contribuir com a formação humanística de todos os envolvidos, por meio da integração universidade e demandas sociais (universalização do ensino); possibilitar a formação docente (inicial e continuada) para/em PLE, a ampliação de visão de mundo e de conhecimento dos professores e futuros professores envolvidos; promover o diálogo entre línguas e culturas, por meio da prática de uma abordagem comunicativo-humanizadora de ensino de PLE; vislumbrar a quebra de fronteiras geográficas e ideológicas, por meio de processos de desterritorialização e consequentes reterritorializações (MOTA, 2010, p. 49); gerar pesquisas relativas ao ensino e à formação docente em PLE, sob o prisma da Linguística Aplicada (LA); divulgar a instituição, a cidade e a região como polos de acolhimento social e linguístico-cultural de estrangeiros de diferentes origens.

Em relação ao grupo no Facebook, de status privado, ao qual somente os membros têm acesso (professores, alunos estrangeiros e coordenadora do projeto), seu intuito é a "troca de informações, avisos, tarefas, fotos e outras atividades relativas ao Projeto de Extensão 'Português Língua Estrangeira' do IBILCE-UNESP”, conforme descrição do grupo (ver Figura 1), onde é comum o uso de textos multimodais para atingir o objetivo descrito. Dessa maneira, buscamos instaurar um clima de interação espontânea, gerando uma aprendizagem (ou um reforço dela) que acreditamos ser mais humanizada e significativa.

Figura 1 - Página inicial do grupo privado PLE-IBILCE

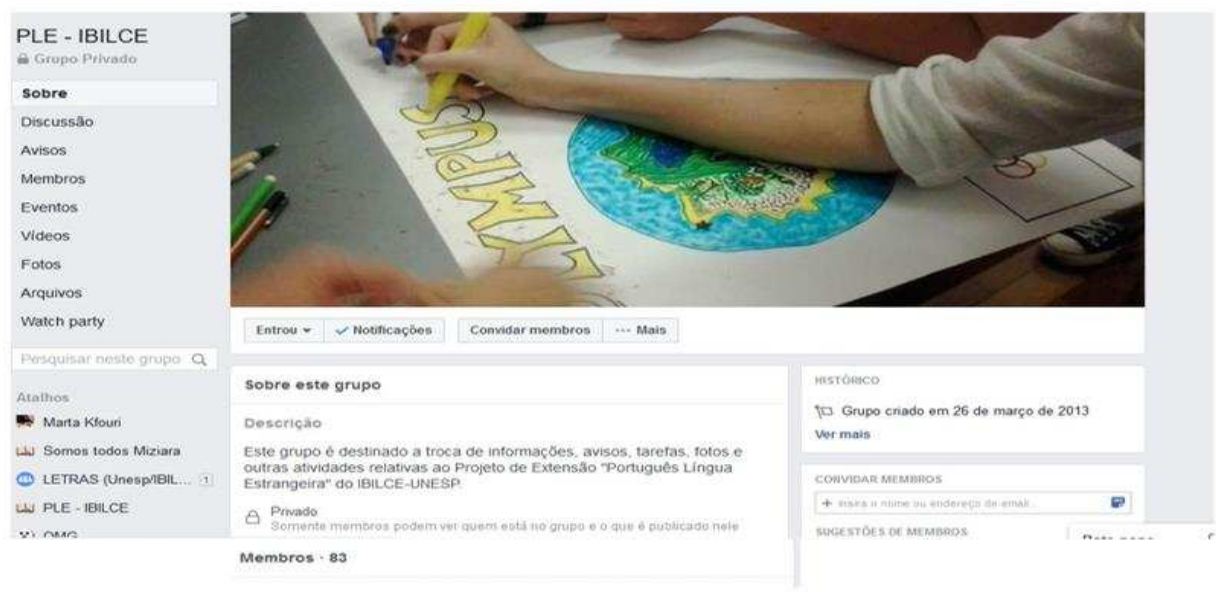

Fonte: Acervo da autora 


\section{Reflexões conceituais pertinentes}

Textos multimodais ou multissemióticos são novas composições textuais instigadas pela tecnologia, advindas de múltiplas formas de linguagem (escrita, oral, visual). A ampla presença de elementos imagéticos e visuais, mesclando escrita e imagem, amplia as possibilidades de comunicação e compreensão do texto, constituído tanto de elementos verbais quanto visuais (SILVA, 2013). Texto, assim, passa a ser definido como toda produção linguística que possa fazer sentido numa situação de comunicação humana (COSTA VAL, 2004), promovendo a compreensão significativa da língua.

Em relação às redes sociais, ainda que o Facebook não tenha sido criado com propósitos educacionais, revelou-se, no caso do Projeto PLE em questão, como ambiente com potencial para a concretização da aprendizagem, por suas possibilidades de interação, socialização e comunicação na língua-alvo, funcionando como ferramenta de aprendizagem colaborativa online (FINARDI; PORCINO, 2016). Conforme já mencionado, os usos de textos multimodais, por suas caraterísticas, promoveram importante relação entre conteúdos já trabalhados nas aulas e outros complementares, permitindo a expansão de seus usos e de sua compreensão. Outras vantagens pedagógicas e humanizadoras do Facebook percebidas nas interações foram a diminuição das relações de poder entre professor e alunos, a substituição de sistemas de gerenciamento formais (aumento da autonomia), além de novas formas menos sistematizadas de tratar o conhecimento. Temos, na verdade, uma (co)construção do conhecimento, por meio da aprendizagem participativa, da autoridade compartilhada e da expansão do modelo presencial em ambiente digital (ALEGRETTI et al., 2012).

$\mathrm{O}$ uso do Facebook na aprendizagem de línguas também pode se alinhar aos pressupostos da teoria sociocultural de Vygotsky (1999), para quem o desenvolvimento humano e a construção do conhecimento e das identidades se dão na mediação pelo pensamento e a linguagem. Em relação à aprendizagem de PLE em foco, a referida rede social favorece o uso específico do idioma selecionado para a comunicação, promovendo construções mais significativas e autênticas da língua-cultura. Assim, estruturas lexicais e sintáticas passam a ser também mais adequadas ao contexto e à produção de um insumo mais compreensível na língua-alvo, promovendo a ativação de fatores emocionais positivos, como a empatia, o fortalecimento das relações entre os participantes, a autoconfiança e a motivação para aprender e usar/viver a língua. A interação continuada, promovida pelos administradores da página, no caso coordenadora e professores do projeto de extensão, auxilia no desenvolvimento da competência comunicativa na língua-alvo (ARAGÃO; DIAS, 2016). 
Essas atitudes positivas se refletem na sala de aula presencial, melhorando, consequentemente, o trabalho desenvolvido e as interações entre falantes de línguas tão diferentes, como é o caso de nosso contexto multicultural ${ }^{5}$.

Faz-se importante ressaltar que a conexão dos participantes em um grupo de rede social (no caso, privado) aumentou-lhes a confiança entre si, a disposição para a aprendizagem e, consequentemente, para agir e demonstrar emoções. Conforme Aragão e Dias (2016), aspectos emocionais contagiam. Portanto, podemos afirmar que se instaurou uma linguagem mais humanizadora por meio das relações no grupo do Facebook, especialmente promovida pelo humor contido nas mensagens dos memes.

Nesse sentido, apesar de gerenciador do grupo, o professor não é o único a ter voz em uma rede social com configurações pedagógicas, como nesse caso. Os aprendizes também precisam compreender e expor seus pontos de vista a respeito da heterogeneidade de culturas, povos, línguas e linguagens. O papel do professor passa a ser o de articulador de muitas vozes, variedades linguísticas e culturais (KFOURI-KANEOYA, 2008), que devem aparecer contextualmente, compartilhando com alunos estrangeiros a língua que ensina em funcionamento e refletindo com eles sobre as variações linguísticas e culturais existentes em seu país, tal como ocorre no país de origem desses estudantes. Além disso, o professor assume-se, ainda, como agregador de identidades culturais e promotor de uma linguagem humanizadora (MATOS, 2010), por meio de uma percepção intercultural que valoriza a comunicação criativa, minimiza, esclarece e contextualiza os choques culturais, promovendo a competência linguístico-cultural. Assim, professor e alunos passam a observar os efeitos positivos da comunicação, buscando humanizar as concepções de mundo e reorganizar identidades multiculturais, ao se verem na perspectiva do outro (MATOS, 2014).

O professor de PLE, em seu papel de agente interculturalista e humanizador, exerce diversas tarefas em busca da comunicação efetivamente dialógica do grupo, aproveitando aquilo que os aprendizes já conhecem da nova língua, valorizando o conhecimento e a experiência educacional prévios em suas línguas/países de origem e utilizando sua língua materna com cuidado, a fim de proporcionar uma aprendizagem adequada e significativa. De acordo com Little (2002), o professor que ensina sua língua como estrangeira tem potencial para desenvolver em si uma consciência metalinguística, sobretudo pelo fato de ter de pensar mais sobre sua a própria língua para ensiná-la a falantes de línguas diversas. Além disso,

${ }^{5}$ Ao longo de nove anos de atividade, o "Projeto de Extensão Português Língua Estrangeira (PLE)" já atendeu, até o momento, estrangeiros de trinta e quatro origens distintas e experiências diversas (pessoais, profissionais e de língua-cultura), caracterizando-se como um contexto multilíngue e multicultural (OLIVEIRA, 2014). 
promove uma base humanizadora para a discussão de questionamentos internacionais, prevalecendo uma dialética entre o global e o nacional/local, a mediação multicultural (FAIRCLOUGH, 2001).

Por fim, ao usarmos o Facebook como ambiente de complementação da aprendizagem e de interação ampliada, compreendemos mais nitidamente que a língua não é mero instrumento a ser dominado pelo aprendiz em estruturas gramaticais ou situações comunicativas pré-definidas. Aprender línguas caracteriza-se como um processo intercultural, discursivo, relacionado diretamente à identidade sociocultural, no qual predomina uma dimensão afetiva subjacente à perspectiva interculturalista na aprendizagem de línguas, que constitui a subjetividade e a identidade linguístico-cultural dos seres discursivos (SERRANI, 2005). Assim, a língua e a cultura estrangeiras são reveladoras da língua e da cultura maternas, e ensinar e aprender envolvem observar os efeitos da comunicação no outro (MATOS, 2010).

\section{Textos multimodais no PLE: estratégias metodológicas e seus efeitos}

Conforme salientamos, os textos multimodais têm funcionado, nas aulas de PLE do projeto enfocado, como um rico recurso para complementação da aprendizagem e humanização das interações, especialmente em ambiente de rede social. A seguir, apresentamos algumas estratégias metodológicas desenvolvidas com a finalidade de usar textos multimodais para ilustrar ou complementar pontos da língua e da cultura trabalhados nas aulas, bem como seus efeitos para potencializar a aprendizagem de PLE, na rede social Facebook 
Estratégia 1: Uso de textos multimodais para ilustrar expressões da língua de uso coloquial/gírias

Figura 2 - Uso de meme para explicar a expressão idiomática "quebrar um galho"

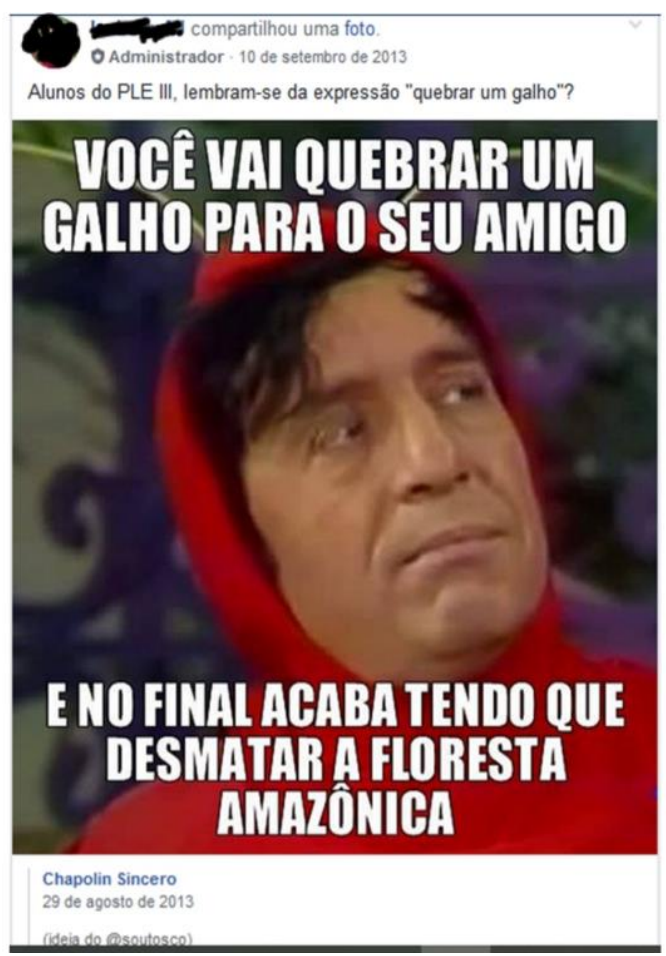

Fonte: Acervo da autora

Figura 3 - Uso de cartaz de filme (mídia visual) para explicar a expressão/título do filme "Minha mãe é uma peça"

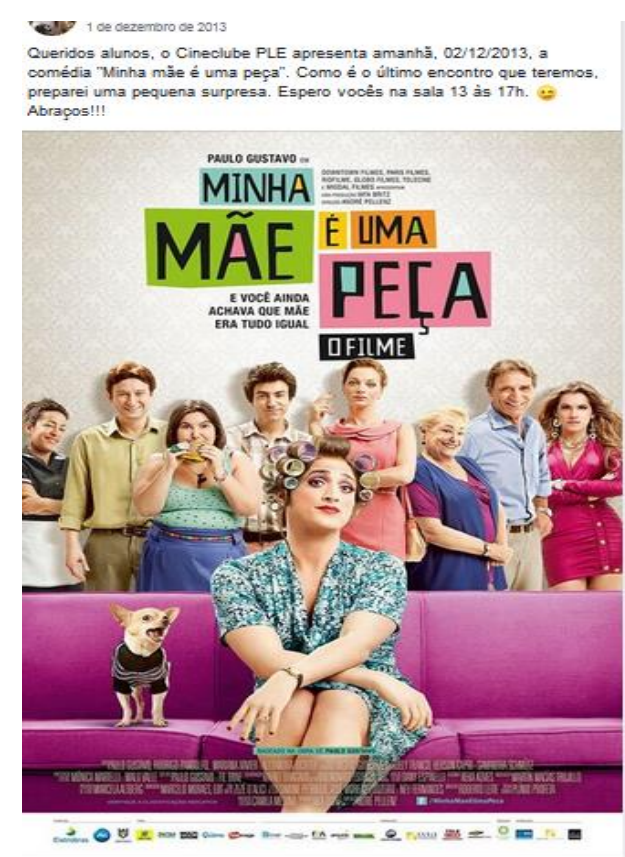

Fonte: Acervo da autora 
Figura 4 - Comentários gerados na página do Facebook a partir do trabalho com o filme

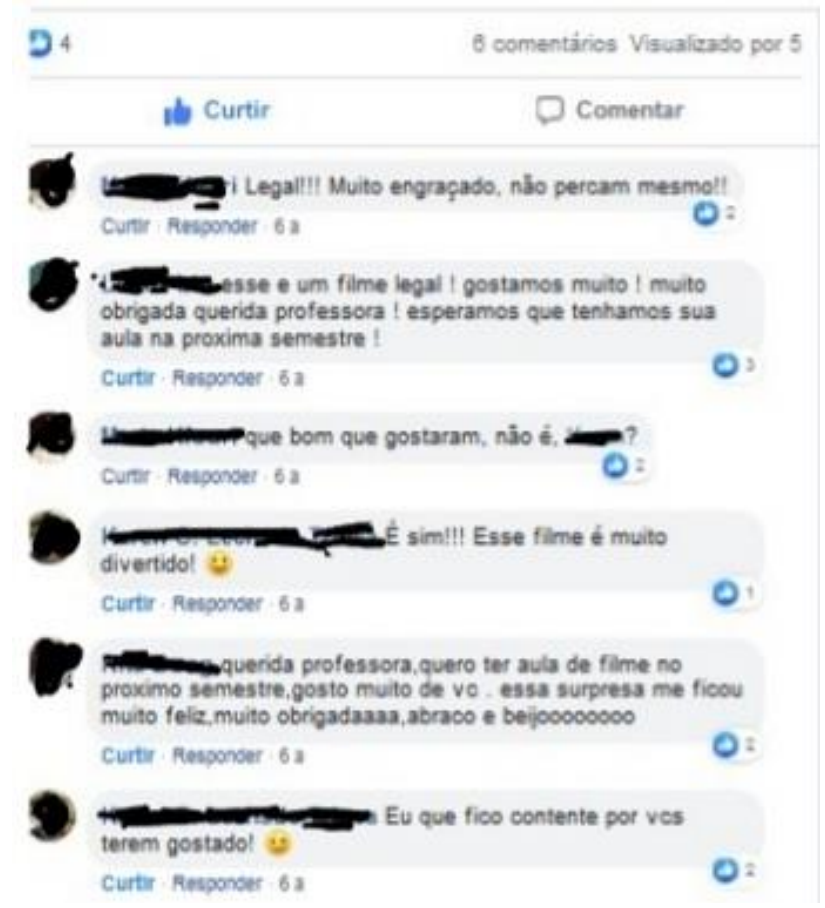

Fonte: Acervo da autora

Figura 5 - Post usado para ilustrar a expressão idiomática "fala mais que o homem da cobra"

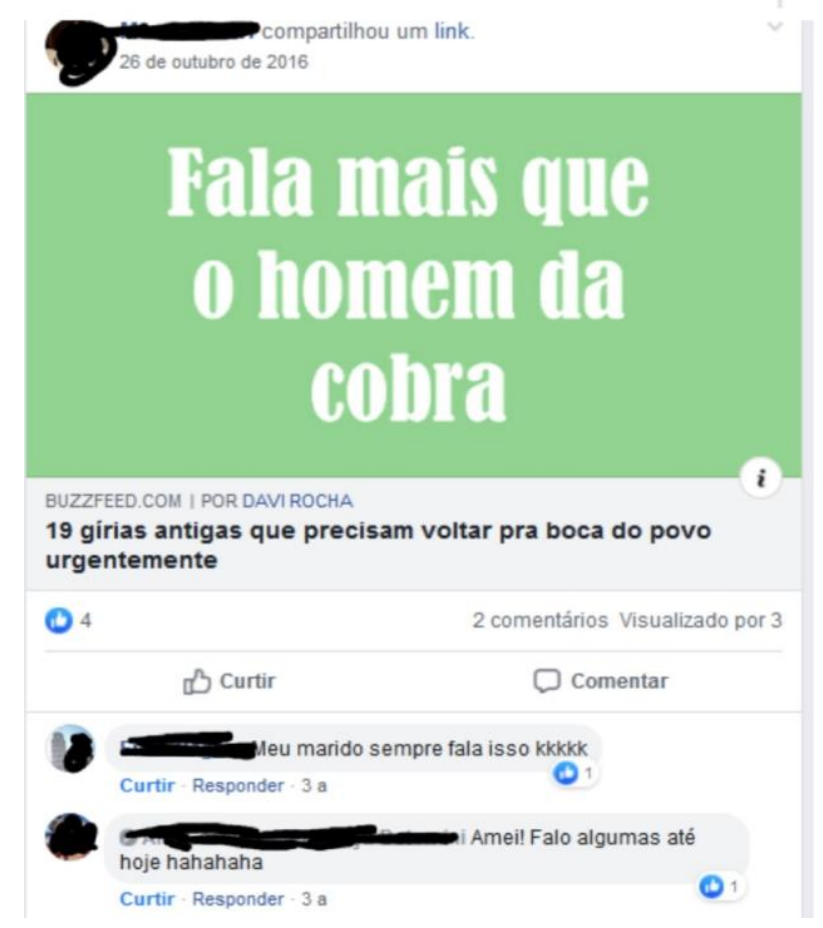

Fonte: Acervo da autora 


\section{Estratégia 2: Uso de textos multimodais para ilustrar variações linguísticas}

Figura 6 - Meme utilizado para ilustrar variação linguística quanto à palavra "veja"

Fonte: Acervo da autora

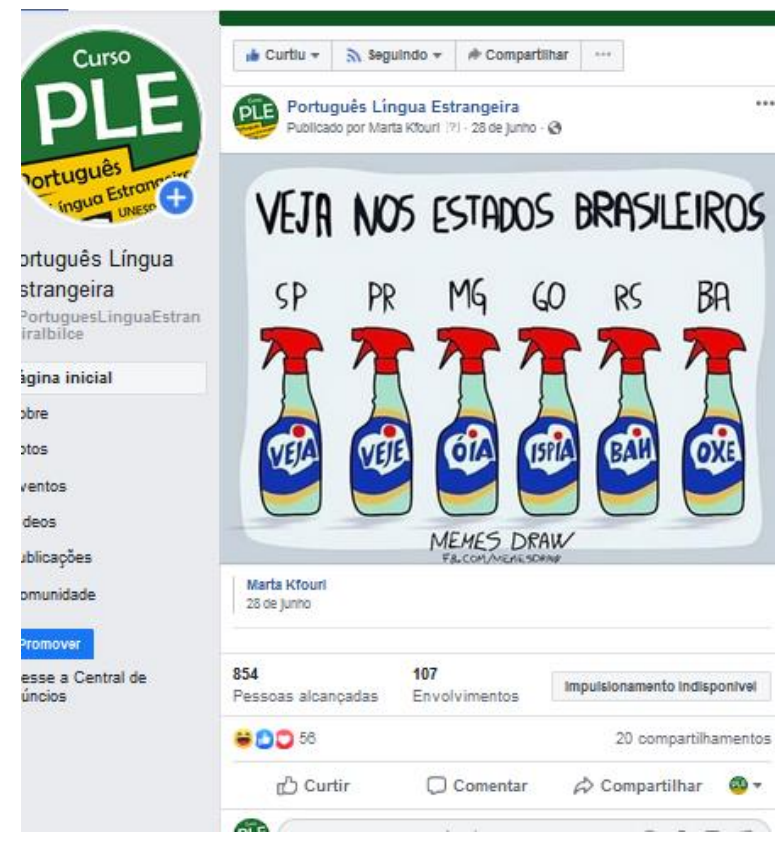

Figura 7 - Meme utilizado para ilustrar variação linguística na caracterização do povo nordestino

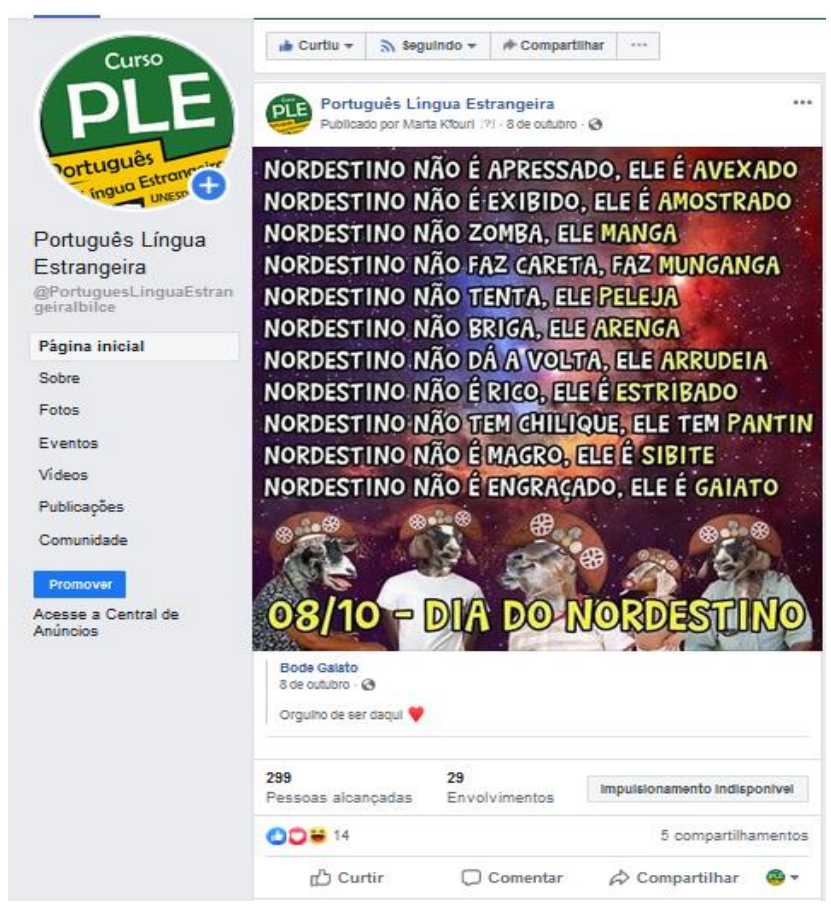

Fonte: Acervo da autora 


\section{Estratégia 3: Uso de textos multimodais para ilustrar questões de fonética e fonologia}

Figura 8 - Meme utilizado para ilustrar questão de fonética por meio de piada

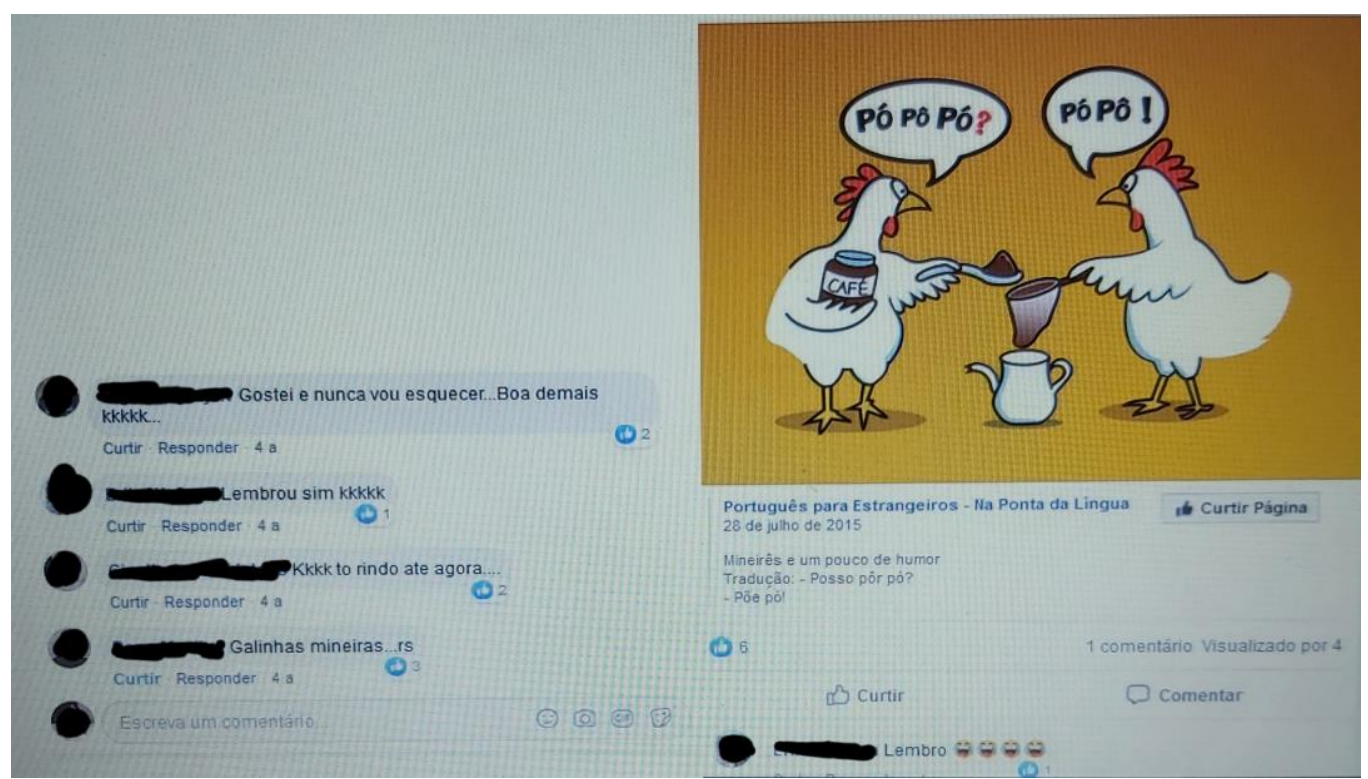

Fonte: Acervo da autora

\section{Estratégia 4: Uso de textos multimodais para ilustrar questões de léxico}

Figura 9 - Uso de fotos em post para ilustrar léxico sobre frutas

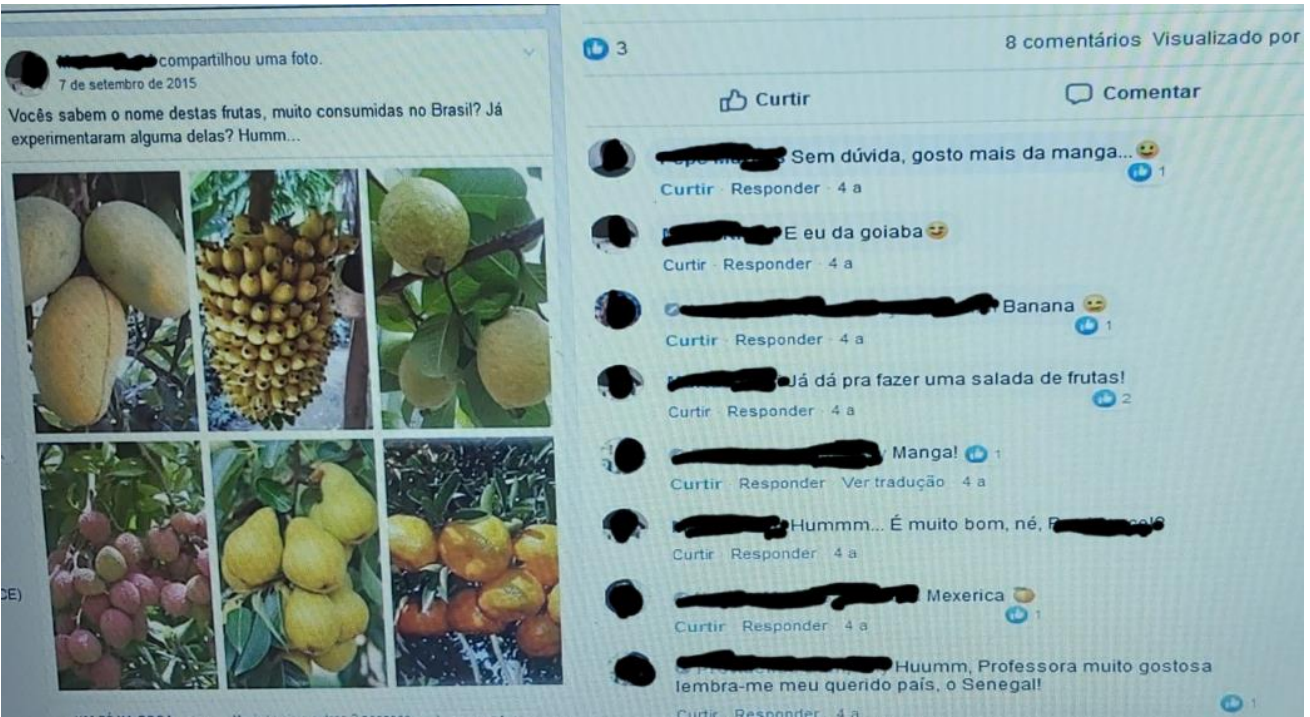

Fonte: Acervo da autora 
Figura 10 - Uso de fotos em post para ilustrar léxico sobre pratos típicos

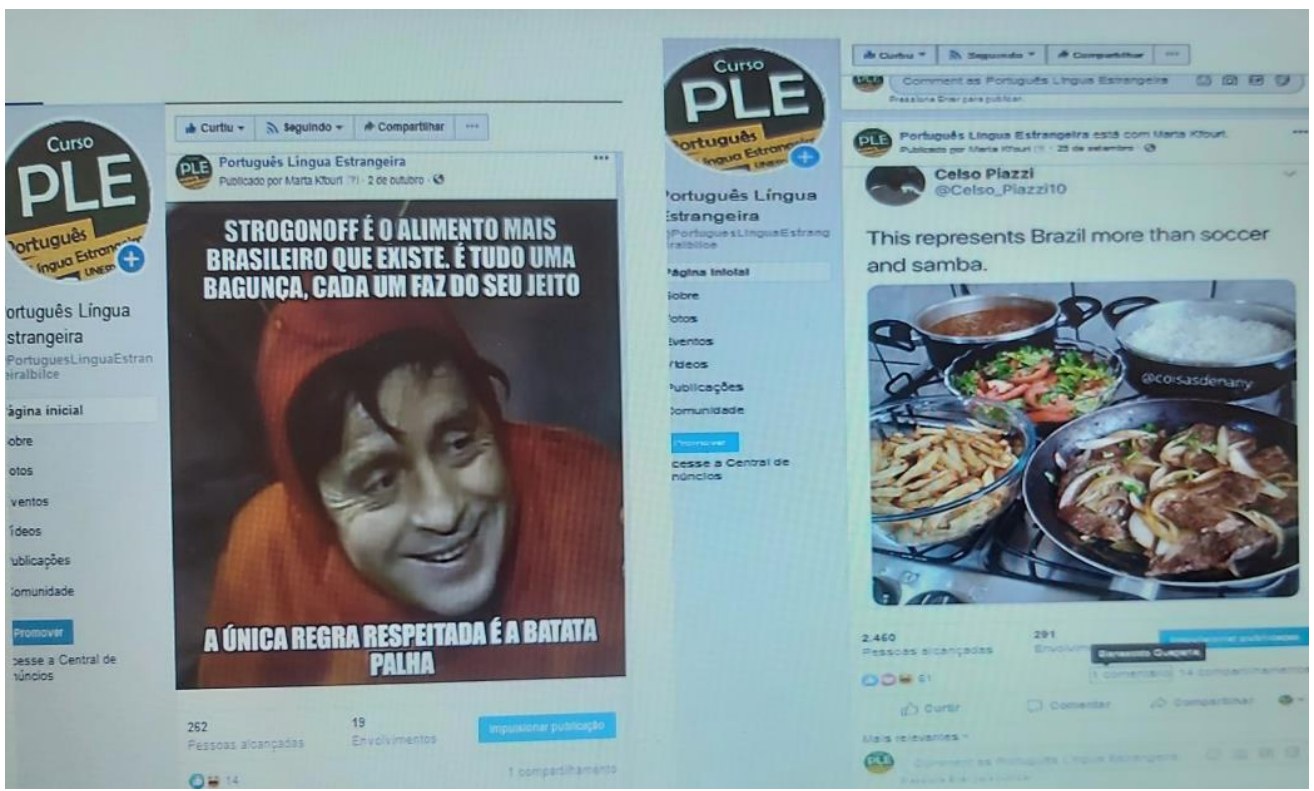

Fonte: Acervo da autora

Figura 11 - Uso de fotos em post para ilustrar o salgado "coxinha"

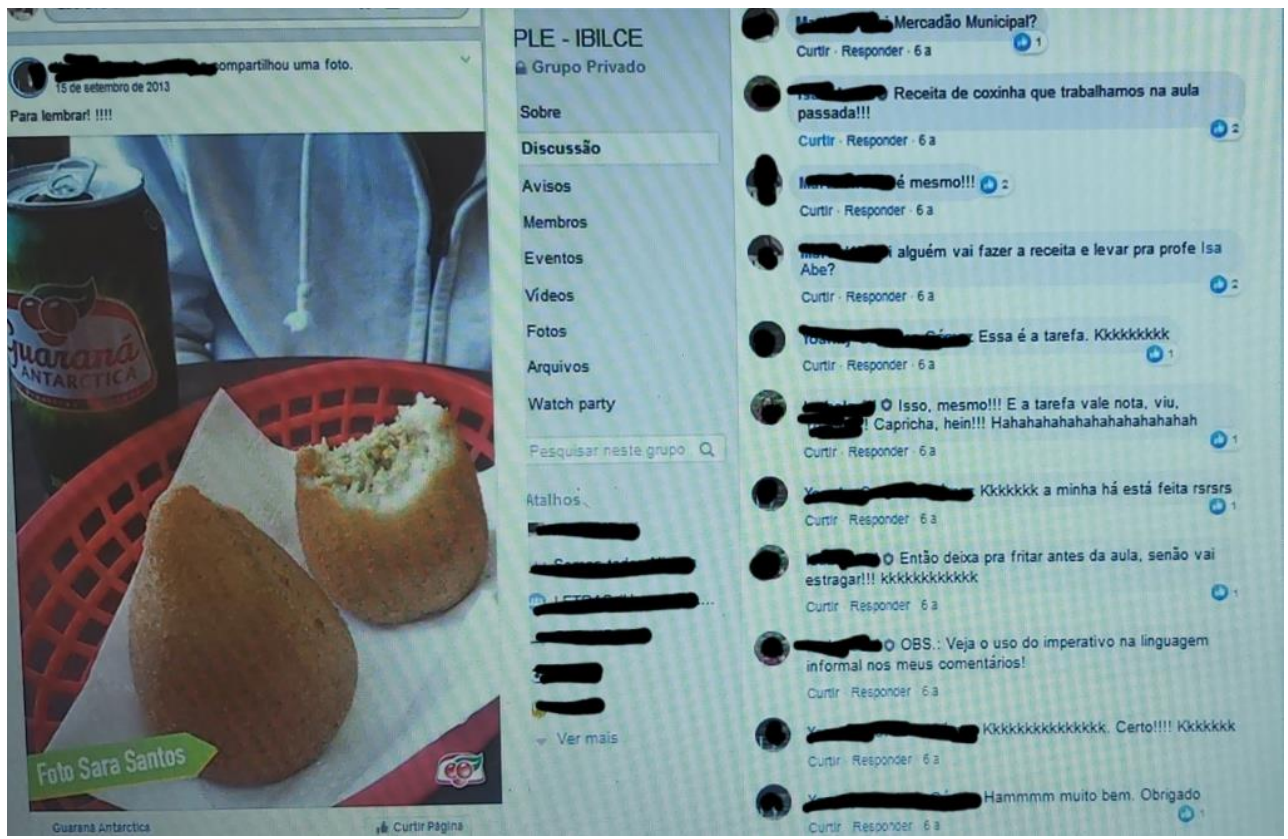

Fonte: Acervo da autora 


\section{Estratégia 5: Uso de textos multimodais para ilustrar o uso de expressões de polidez}

Figura 12 - Uso de memes, ilustrações e quadrinhos para ilustrar o uso de expressões de polidez

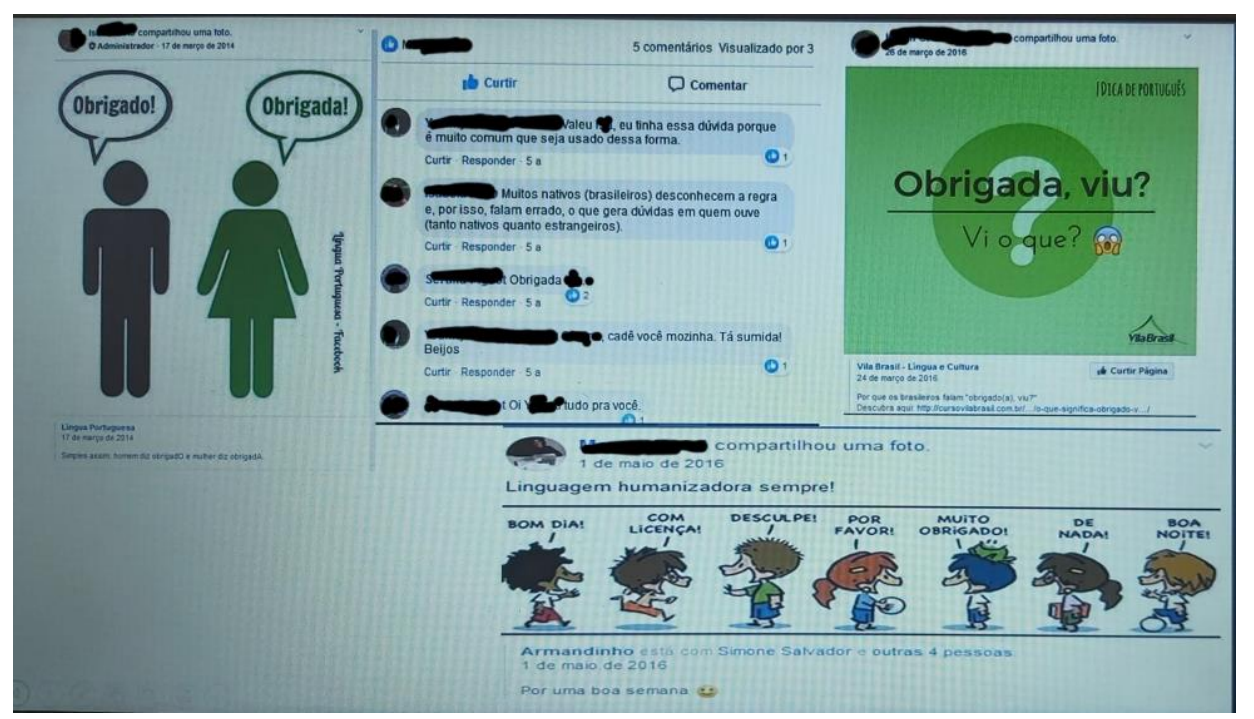

Fonte: Acervo da autora

Podemos notar em todas as figuras acima o nítido reforço da aprendizagem dos temas abordados nas aulas presenciais, bem como o envolvimento humanizador e afetivo de todos os participantes (administradores/professores do grupo e alunos estrangeiros) por meio de recursos multimodais e do emprego de uma linguagem informal, típica da rede social, porém, reforçadora da aprendizagem e das interações significativas entre os integrantes do grupo. $\mathrm{O}$ uso de uma linguagem humanizadora para construir o discurso e envolver os aprendizes na proposta dos posts aparece em vários momentos das estratégias elencadas, como em "Queridos alunos" e "Abraços" (figura 3), "alunos do PLE III (figura 2), bem como nos comentários positivos gerados a partir dos posts, quase sempre associados a experiências pessoais dos estrangeiros, tais como: "Gostamos muito" (figura 4), "Meu marido sempre fala isso kkk" e "Amei! Falo algumas até hoje hahaha" (figura 5), "Gostei e nunca vou esquecer...boa demais kkk" (figura 8), "Humm... professora, muito gostosa. Lembra-me meu querido país, o Senegal” (figura 9). Nas figuras 11 e 12, constatamos que a professora utiliza o contexto da postagem para, no primeiro caso, reforçar e envolver os alunos na atividade proposta em sala de aula como tarefa (fazer e levar para a aula uma receita de coxinha) e, no segundo, reforçar o uso de "obrigado" e "obrigada". Em relação às postagens onde não há comentários explícitos, o uso de emojis como "positivo", indicado pelo polegar levantado, coração e gargalhada também denotam o envolvimento emocional positivo dos participantes em torno da aprendizagem de PLE. 


\section{Considerações finais}

No contexto de projeto de extensão em PLE apresentado, visualizamos o uso de textos multimodais como um recurso essencial para a ressignificação da aprendizagem, a compreensão da língua-cultura em foco e de possibilidades de ensino interculturalista e humanizador, sobretudo em ambiente de rede social como o grupo de Facebook. O Projeto PLE é, ainda, um ambiente fundamental e antecipador no oferecimento de espaço para a formação de interagentes conscientes do poder emancipatório da comunicação pelas línguas, no sentido de favorecer a interculturalidade, celebrar as diferenças linguístico-culturais e lidar com a diversidade, sobretudo quando se trata de um país com dimensões continentais como o Brasil. Essa atitude, sem dúvida, favorece também a formação inicial e continuada docente em/para o PLE, em um campus universitário onde ainda não há essa licenciatura, no sentido de levar futuros professores a refletir sobre ensinar sua própria língua como estrangeira, tendo por aliada a internet e seus recursos. Complementarmente, visualizamos que o Projeto ultrapassa as delimitações de um trabalho de extensão à comunidade local, atingindo os âmbitos social, político e humanitário, e quebrando fronteiras, em contexto global. O Projeto PLE é cenário de ensino interculturalista e de formação humanizadora de professores de PLE, vislumbrando sua atuação em novos contextos pós-pandêmicos, nos quais a tecnologia estará massivamente presente.

\section{REFERÊNCIAS}

ALLEGRETTI, S. M. M. et al. Aprendizagem nas redes sociais virtuais: o potencial da conectividade em dois cenários. Revista Contemporaneidade Educação e Tecnologia, v. 1, n. 2, p. 53-60, 2012.

ARAGÃO, R.; DIAS, I. A. Facebook e emoções de estudantes no uso de inglês. In:

ARAÚJO, J; LEFFA, V. (org.). Redes sociais e ensino de línguas: o que temos de aprender? São Paulo: Parábola Editorial, 2016. p. 111-121.

COSTA, V. M. G. F. Texto, textualidade e textualização. Pedagogia Cidadã - Cadernos de Formação Língua Portuguesa, São Paulo, v. 1, p. 113-124, 2004.

FAIRCLOUGH, N. Language and Power. London: Longman, 2001.

FINARDI, F.; PORCINO, M. C. Facebook na ensinagem de inglês como língua adicional. In: ARAÚJO, J; LEFFA, V. (org.). Redes sociais e ensino de línguas: o que temos de aprender? São Paulo: Parábola Editorial, 2016. p. 93-109. 
MATOS, F. C. G. Como usar uma linguagem humanizadora: orientação para professores de línguas estrangeiras. In: MOTA, K; SCHEYERL, D. (org.). Recortes Interculturais na Sala de Aula de Línguas Estrangeiras. Salvador: EDUFBA, 2010. p. 24-36.

MATOS, F. C. G. Peace linguistics for language teachers. D.E.L.T.A., v. 30, n. 2, p.415-424, 2014.

KFOURI-KANEOYA, M. L. C. A formação Inicial de professoras para/em contextos mediado pelo computador (teletandem): um diálogo entre crenças, discurso e reflexão profissional. Tese de doutorado. São José do Rio Preto, SP: IBILCE/UNESP, 2008.

LITTLE, D. A aprendizagem de línguas em tandem e a autonomia do aprendente. In: DELILLE, K. H.; CHICHORRO, A. (Eds.). Aprendizagem autônoma de línguas em Tandem. Lisboa: Colibri, 2002. p. 27-35.

MOITA LOPES, L.P. (org.). O Português no Século XXI. São Paulo: Parábola Editorial, 2013.

MOTA, K.M.S. Incluindo as diferenças, resgatando o coletivo - novas perspectivas multiculturais no ensino de línguas estrangeiras. In: MOTA, K.; SCHEYERL, D. (org.). Recortes Interculturais na Sala de Aula de Línguas Estrangeiras. Salvador, BA: EDUFBA, 2010. p. 37-62.

SERRANI, S. Discurso e cultura na aula de língua: currículo: leitura- escrita. Campinas, SP: Pontes, 2005.

SILVA, S.P. Multimodalidade: afinal, o que é? Observatório da Imprensa, Campinas, $\mathrm{n}$. 768, p. $01-02,15$ out. 2013.

VYGOTSKY, L. V. Pensamento e linguagem. 3. ed. São Paulo: Martins Fontes, 1999.

\section{Como referenciar este artigo}

KFOURI, M. L. C. Promovendo o ensino de Português Língua Estrangeira mediado por textos multimodais em práticas extensionistas. Rev. EntreLínguas, Araraquara, v. 7, n. esp. 6, e021154, dez. 2021. e-ISSN: 2447-3529. DOI: https://doi.org/10.29051/el.v7iesp.6.15469

Submetido em: $26 / 08 / 2021$

Revisões requeridas em: 10/10/2021

Aprovado em: 25/11/2021

Publicado em: 28/12/2021 